\title{
Pelos olhos de uma criança: as ditaduras militares latino-americanas no cinema contemporâneo
}

\author{
Fernanda Luiza Teixeira Lima* \\ Luiz Estevam de Oliveira Fernandes ${ }^{* \star}$
}

Resumo: Neste artigo, refletimos sobre como alguns cineastas têm retratado o passado recente das ditaduras militares em seus filmes. Abordaremos o tema a partir de um recorte bastante comum adotado por alguns filmes: a estratégia discursiva de montar filmes a partir do olhar de protagonistas crianças. Para isso discutiremos o debate entre história e cinema e analisaremos os filmes: Kamchatka (Marcelo Piñeyro, Argentina, 2002), Machuca (Andrés Wood, Chile, 2004) e O ano em que meus pais saíram de férias (Cao Hamburguer, Brasil, 2006). Verificaremos como, ao lidar com "passados doloridos", com um objeto ainda quente, o olhar infantil enreda a narrativa em uma aura de inocência perdida e de fim de ilusões infantis por meio de uma experiência traumática. E o trauma pessoal passa a ser a metonímia (muitas vezes autobiográfica) daquilo que é visto como um trauma coletivo.

Palavras-Chave: Ditadura. América Latina. Memória. Cinema. Infância.

\footnotetext{
* Pesquisadora da área de História da América, desenvolve trabalhos acerca das relações entre a história e o cinema latino-americano sobre o período da ditadura militar da América do Sul no século XX, tendo como um dos objetivos específicos estudar a representação do regime da ditadura chilena (1973-1990), através dos filmes Machuca (2004) e Tony Manero (2008) e investigar as relações que esses filmes estabelecem com o trabalho de memória e luto no país. E-mail: fernandaluizatlima@yahoo.com.br.

** Professor adjunto da Universidade Federal de Ouro Preto e pesquisador colaborador do Departamento de História do IFCH-Unicamp. E-mail: leof79@gmail.com.
} 
Pelos olhos de uma criança: as ditaduras militares latino-americanas...

\section{Introdução}

O historiador argentino Luis Alberto Romero (2007, p. 9-23) afirmou em artigo recente que a construção da memória e da história "esquenta" ou "esfria" de acordo com o objeto com que lidam. Um objeto seria "frio" caso se tratasse, por exemplo, da memória construída sobre o passado monárquico e republicano romano durante o Império. A "temperatura aumentaria" se o tema fosse a memória da nação e seus mitos de origem. Atingiriam seu "ponto máximo" quando se tratasse da memória do passado recente, ou melhor, daquela parte do "passado recente que ainda dói no presente".

Em outras palavras, "o passado que dói" seria aquele que ainda tem estreita conexão com o mundo em que vivemos e atuamos. No caso latino-americano, esse passado seria o militar e o da nossa recente experiência democrática. Tais questões ainda provocam muitas controvérsias, e se confundem com militância política mais frequentemente do que ocorreria em temas mais "frios".

A partir de uma questão silenciada, a do trauma da ditadura narrado nos filmes através da inocência do olhar infantil, nosso artigo configura-se dentro de um cenário entre "a tensão entre a 'memória viva' e a 'história escrita' visando ao presente."1 Pensando o lugar de produção do filme, a pergunta a se fazer não é como o filme representa a ditadura, mas qual é o papel dessa representação? Por que o tema da ditadura serve mais do que nunca de enredo na construção dos filmes desses países? É possível mapear a experiência pessoal do diretor como forma de se pensar a maneira pela qual ele aborda a experiência maior de uma coletividade?

Nosso referencial teórico-metodológico se insere no interior do debate entre história e cinema. Um dos aspectos mais debatidos na relação entre esses campos é aquele que entende o filme como documento histórico. Essa noção do cinema como fonte histórica iniciou-se a partir da década de 1970, a partir da Nova História francesa. Naquele momento, o historiador Marc Ferro, na sua obra Cinema e História, postulou que, através da "operação histórica", o cinema poderia ser incorporado como objeto da historiografia.

Nessa linha, em hipótese apresentada por Francisco das Chagas Fernandes Júnior: "[...] a fundação do cinema como objeto bisto- 
riográfico deu-se pela exclusão do debate direto com os estudos do cinema e com a história do cinema" (2012, p. 153). Ou seja, para o autor, formaram-se dois tipos de discussões: a primeira, que enxergou o cinema como um objeto com um fim em si mesmo e suas relações com as teorias do cinema, e a segunda, pensando os filmes como fonte para analisar a sociedade.

Essa nova possibilidade de se pensar as obras fílmicas sob uma perspectiva dos estudos históricos recebeu um conjunto de críticas no que se refere à ênfase dada às imagens, como se elas por si só bastassem como discurso. Essas críticas se deram sob o fato de muitos estudos sobre o cinema, até então, pensarem apenas (ou com muita ênfase) numa abordagem estética, como se a captação de imagens fosse feita de forma neutra e objetiva, sem levar em consideração as intenções de quem as produziu.

Também houve estudos baseados nas teorias de Ferro que criaram o que se convencionou chamar de proposta sociológica. Grosso modo, são estudos que se propunham a pensar os filmes como reflexo das sociedades e dos objetos que retratavam. Pensar dessa forma implicava dizer que o filme (assim como outras obras de arte ou da indústria) eram frutos da época e das pessoas que os produziram. Inaugurando um campo bastante interessante, essa perspectiva tornou possível pensar as produções fílmicas para além de seus aspectos estéticos, trabalhando valores, intencionalidades e até mesmo ideologias que os filmes carregavam.

Contrapondo-se à perspectiva meramente estética, temos os trabalhos de Pierre Sorlin. Seus escritos são baseados em filmes históricos e também trazem proposições frente à proposta sociológica. $\mathrm{O}$ autor lembra que os filmes devem ser compreendidos em suas especificidades, entendendo a relação do filme com o período que ele deseja representar e, principalmente, com seu presente. Para o autor, o importante não seria definir o que o filme pretende dizer, mas o que diz e como diz. Como mencionado por Chagas: "[...] divergentes em alguns pontos, as propostas de Marc Ferro e Pierre Sorlin convergiam na centralização do filme como objeto central de uma dupla preocupação: película como documento ou como representação da história” (2011, p.155). 
No Brasil, a discussão tem seu marco na década de 1980, quando Mônica Kornis, Alcides Freire Ramos, Jean-Claude Bernadet e Jorge Nóvoa dedicaram-se a ultrapassar o enfoque da sociologia e economia histórica do filme como reflexo social. Para Nóvoa: "[...] o cinema é história, imagem ou não da realidade, documentário ou ficção" (1995, p. 109). Mas, "[...] não é a obra de arte em si, nem a história desse gênero que está em jogo" (1995). O filme passava a ser visto como uma construção que, como tal, altera a realidade através de uma articulação entre a imagem, a palavra, o som e o movimento. Como demonstra Mônica Kornis "[...] os vários elementos da confecção de um filme - a montagem, o enquadramento, os movimentos de câmera, a iluminação, a utilização ou não da cor - são elementos estéticos que formam a linguagem cinematográfica, conferindo-lhe um significado específico que transforma e interpreta aquilo que foi recortado do real" (KORNIS, 1992, p. 3).

A questão central que se coloca para o historiador que quer trabalhar com a imagem cinematográfica diz respeito exatamente a este ponto: o que a imagem reflete ou instaura? Ela é a expressão da realidade ou é uma representação? Qual é o grau possível de manipulação da imagem? Ou, até mesmo, qual o grau de ligação de um discurso fílmico com a noção de realidade?

É importante reafirmar que o filme, assim como as produções históricas, é uma interpretação de um tema. Julgar um filme somente pela fidelidade ou pela reconstituição fidedigna à época é considerar que ele pode revelar uma suposta verdade histórica. $\mathrm{O}$ embasamento do nosso artigo configura-se dentro de um conjunto que discute relações mais amplas entre cinema e história. A questão da recepção do filme não será ponto de discussão neste trabalho, visto que nos interessa mais compreendê-lo em suas condições de produção e de produção de discurso. Concordamos com Maria Helena Capelato quando esta define o filme como documento de discussão de uma época e seu estatuto como objeto da cultura que encena o passado e expressa o presente (CAPELATO, 2007, p. 10). Podemos dizer, então, que o filme, como obra de arte, faz mais do que retratar o real, ele o reinventa, como obra de arte.

Dessa forma, analisaremos três filmes: Kamchatka (Marcelo Piñeyro, Argentina, 2002), Machuca (Andrés Wood, Chile, 2004) e 
$O$ ano que meus pais saíram de férias (Cao Hamburguer, Brasil, 2006). Vale ressaltar que, em comum, todos são narrados em primeira pessoa por meninos que viveram durante o período ditatorial de seus países e que a classificação indicativa de cada filme não se enquadra dentro do gênero infantil.

\section{Um lugar para resistir: Kamchatka e a questão dos desaparecidos}

Kamchatka é um filme de 2001, de grande alcance popular na Argentina e premiado internacionalmente. A película se passa na década de 1970, durante o mandato de Jorge Rafael Videla, ainda nos primeiros anos da ditadura. O período ditatorial da Argentina foi de 1976 a 1983, e insere-se em um contexto de grave crise política e econômica. Assim como em outros países da América Latina, o Estado sofria com a inflação e com a estagnação da economia. Segundo Luis Alberto Romero (2007, p.196):

O caos econômico de 1975, a crise de autoridade, as lutas facciosas, a presença cotidiana da morte, a ação espetacular das organizações guerrilheiras - que fracassaram em duas grandes operações contra unidades militares na grande Buenos Aires e em Formosa - e o terror semeado pelo Triplo A, tudo isso criou as condições para aceitação de um golpe de Estado, que prometia restabelecer a ordem e assegurar o monopólio estatal da força.

A proposta era "reeducar" a sociedade. Para isso, desmontaram-se estruturas formais e informais de proteção estatal que haviam sido criadas na década de 1930 na primeira fase do peronismo. Dessa forma, era comum a perseguição a profissionais do meio burocrático estatal, como aquele representado por Ricardo Darín, que no filme interpreta um advogado casado com uma cientista (Cecília Roth), pais do pequeno Harry (Matías Del Pozo), de 10 anos, narrador do filme. Por conta do envolvimento do casal 
Pelos olhos de uma criança: as ditaduras militares latino-americanas...

com a militância contra o governo, a família foge para um sítio distante do centro de Buenos Aires. A mudança afeta o cotidiano de Harry e o de sua família, uma vez que eles são obrigados a mudar de identidade, escola e trabalho, vivendo em constante estado de alerta em meio às mudanças de hábito.

É a voz de Harry, em off, que abre o filme, indagando sobre os mistérios da origem do Homem, ao mesmo tempo em que compara esses mistérios aos acontecimentos de sua vida, num claro exemplo da metonímia, fruto deste objeto de análise, ou seja, de uma experiência individual que é, nesses filmes, um microcosmo de uma experiência maior e coletiva. Entendemos que Harry já é um adulto, apesar de não ser apresentado como tal, uma vez que ouvimos sua voz de criança. Mas, a clarividência da narrativa nos faz crer que ele fala de eventos já passados, em tom de rememoração, conferindo sentido a episódios que, até então, pareciam desconexos e confusos.

O nome verdadeiro de Harry não nos é revelado, tampouco o de seus familiares. $\mathrm{Na}$ verdade, são poucos detalhes que nos são dados sobre a vida da família. Até mesmo o tipo de oposição feita pelos pais de Harry é deixada em aberto: não sabemos de fato se estavam envolvidos com a luta armada ou com outro tipo de ativismo político. Ainda assim, o protagonista tem conhecimento sobre a iminência do perigo que ameaça sua família, mas por ser criança, não compreende o significado da mudança dos acontecimentos em sua vida. Harry, na verdade, descobre a delicada e complexa situação que o levou para o sítio a partir de três elementos do universo infantil: uma série de TV, um jogo e uma história em quadrinhos.

A série de televisão, chamada Los invasores, de ficção científica, conta a história de seres de um planeta extinto que invadem o planeta Terra para dominá-lo. Para o menino, os militares eram associados a invasores de seu país, de seu meio familiar e de sua rotina. Justamente daí vem o nome com o qual o filme identifica o pai de Harry: o nome do herói do seriado, David Vincent, o principal combatente e defensor da terra.

Já o nome de Harry advém da história em quadrinhos que a criança encontra na nova casa onde moram. Nela, o garoto acompanha as aventuras do mágico Harry Houdini, que conseguia se livrar de todas as situações de perigo e aprisionamento a que era

Anos 90, Porto Alegre, v. 20, n. 38, p. 411-439, dez. 2013 
submetido. O menino deseja ser Houdini justamente para aprender a escapar de sua nova realidade e a lidar melhor com sua vida em fuga. Por mais que a família desejasse voltar ao cotidiano anterior, retomando as atividades, como jantar juntos, cantar, ir à escola e visitar a casa dos avós - a vida estava sempre no limiar, sendo que o nome de cada membro representava seu próprio esconderijo. Metaforicamente, podemos pensar na troca dos nomes como um símbolo de resistência e da clandestinidade da família.

Kamchatka, por sua vez, é um local real, uma península russa. Mas, no filme, é apenas um território localizado em um jogo conhecido como TEG (“Tática y estratégia de la guerra”), semelhante ao jogo $W A R$ no Brasil, no qual brincam Harry e seu pai. Em uma cena do filme, os dois aparecem focados em ganhar a disputa e, pela primeira vez, Harry tem a chance de vencer seu pai por estar com a maioria dos países dominados no tabuleiro. Mais uma vez, entretanto, ele não tem sucesso, pois seu pai começa a reconquistar as nações por Kamchatka, seu lugar de resistência no tabuleiro.

Aliás, é o próprio Harry, no encerramento do filme, quem nos revela a metáfora de Kamchatka como um lugar para resistir às mudanças que sua família passou: "Na última vez que o vi, meu pai falou de Kamchatka. Dessa vez, entendi. E cada vez que joguei, meu pai estava comigo. Quando o jogo ficava difícil, eu fazia como ele e sobrevivi. Porque Kamchatka é o lugar de resistir”. Aquele jogo sintetizava a ideia central do filme, no que se refere às estratégias para escapar e resistir à invasão da vida privada causada pela ditadura e à como lidar, no futuro, com aquele "passado que dói".

As amizades de Harry também dão indicativo de sua rotina alterada. Bertuccio, único personagem que possui nome real e não um codinome na trama, é um desses amigos do protagonista. A relação dos dois é interrompida no início do filme, por conta do golpe militar. A nova situação política os obriga a viverem em lados diferentes do conflito: enquanto a família de Bertuccio permanece do lado oficial, a família de Harry "desaparece" na clandestinidade. Os nomes dos personagens são sintomáticos disso: os Bertuccio podem continuar a levar sua existência na oficialidade, na mesma casa, na mesma escola etc., mantendo seus nomes reais. A família de Harry, por sua vez, perde seus nomes originais e passa a viver 
uma nova rotina, de resistência. Tomando como base esse cenário, é recorrente a ideia de que a sociedade argentina parecia dividida entre amantes e inimigos da pátria, assim como os pais de Bertuccio e os pais de Harry na obra.

A nova vida da família de Harry tem sua rotina quebrada com a chegada de um estudante de codinome Lucas para morar com eles. O jovem também está envolvido com a luta política e é acolhido pelos pais de Harry durante um tempo. Com o passar do tempo, Harry torna-se um grande amigo de Lucas por poder compartilhar os mesmos anseios e uma vida similar. Lucas o conquista quando incentiva Harry a treinar como o escapista Houdini. Ainda assim, a vida clandestina faz com que essa amizade torne-se mais uma decepção na vida do narrador: Lucas precisa partir, e o menino, já distante de Bertuccio, perde outro grande amigo e sente seu círculo íntimo se fechar ainda mais.

O diretor opta por conduzir uma narrativa agridoce, aos moldes de A vida é bela, de Roberto Benigni (1997), tratando temas nacionais e de opressão, repressão e fuga, a partir do escopo íntimo de uma família. Assim como a película italiana, o filme de Marcelo Piñeyro pretende provocar momentos de riso e intensidade dramática, tendo como motivo a proteção que um pai, diante de uma situação radicalmente adversa, como o nazifacismo e a perseguição aos judeus, no primeiro caso e a ditadura Argentina e a clandestinidade, no segundo; sobre o qual os filhos têm pouca ou nenhuma consciência.

Também como no filme de 1997, Piñeyro constrói um final dramático, marcado, neste último caso, pelo silêncio. Na cena derradeira, os pais de Harry deixam seu irmão e ele com o avô paterno. $\mathrm{Na}$ medida em que o carro se afasta, o silêncio entre as personagens aumenta, deixando clara a dor da separação como algo indizível. Harry jamais veria os pais novamente. De acordo com Maria Luiza Rodrigues, na Argentina, a chamada guerra contra a subversão - leia-se contra todos/as que opusessem algum tipo de ação e/ ou pensamento distinto do esperado pela Junta - logo começou a produzir seus resultados: nos dois primeiros anos do Proceso de Reorganización Nacional, mais de 10.000 pessoas foram mortas pelas forças repressivas (2007, p. 57), mas o número pode ser bem maior. Especialmente depois das publicações pós-Nunca Más e das 
manifestações como as das mães da praça de maio, cristalizou-se na Argentina, com muita força, a noção do "desaparecido". O desaparecido é aquela pessoa que morreu durante o regime militar, mas sua morte não pode ser comprovada pelo desaparecimento do corpo. Isso ocorreu em vários regimes de exceção e ditaduras (para não dizer em democracias, inclusive), não só na América Latina. Mas, na Argentina essa noção ganhou muita força e aparece no filme.

É preciso ressaltar que, embora a ditadura e os agentes do Estado autoritário não apareçam como elementos centrais da narrativa, a repressão está presente no filme todo por meio dos efeitos que ela causa. Vemos seus efeitos sem ver seus perpetradores. Vemos as mudanças do cenário público e coletivo por meio das mudanças da esfera privada de uma única família. Elas estão presentes nas cenas que exploram a tensão e o medo dos pais em ter que deixar ou perder seus filhos a qualquer momento, por exemplo; ou na própria mudança radical no estilo e local de vida dos protagonistas.

Ao final do filme nenhum dos nomes são revelados e permanece o silêncio de uma memória que só nos é revelada em fragmentos pelo olhar infantil, incapaz de, no momento, dar significado àquela estranha cadeia de mudanças pelas quais passou. A imagem da criança e sua narrativa nos projetam para o futuro, para nosso passado recente, no qual são reconstruídas as memórias dos tempos da ditadura. Nesses termos, podemos inferir que a memória de Harry constitui-se como uma reelaboração do passado violento em tempos atuais.

\section{Machuca: reelaboração do golpe do ponto de vista especular}

Produzido também num contexto de abertura política, $M a$ chuca é um filme chileno-espanhol, dirigido por Andrés Wood, em 2004. Nessa película, o eixo principal é a história de amizade entre dois pré-adolescentes em Santiago, imediatamente antes do golpe militar. A ditadura militar no Chile se instaurou no dia 11 de setembro 1973, após a tomada do Palácio de La Moneda e a morte do presidente Salvador Allende. Toda ação ocorreu rapidamente e 
Pelos olhos de uma criança: as ditaduras militares latino-americanas...

logo o regime tomou os poderes políticos do país. De acordo com Fabiana de Souza Fredrigro "[...] a rapidez da Junta Militar evidenciava que, embora não definido, nos primeiros momentos, se o caráter da ditadura que se instalava era refundador ou restaurador, certamente a atitude golpista vinha por em xeque a atuação política dos partidos". (2005, p. 20)

Peter Winn, em História e Memória no Chile Contemporâneo, fez um levantamento a respeito das informações sobre o regime militar de Pinochet. Segundo o autor, grande parte das informações foi obtida durante a ditadura através das queixas apresentadas pelas vítimas do regime e pelas suas famílias. Porém, essas pessoas ainda enfrentam as organizações de direitos humanos e a morosa transição democrática, por suas declarações à Comissão da verdade, o comitê contra a tortura (WINN, 2010, p. 23-27). Além disso, o governo de Pinochet iniciou uma campanha de desinformação em massa, forjando alguns acontecimentos de ações da esquerda, falsificando documentos, a fim de justificar a sua repressão brutal e eliminar a violência de seus atos (WINN, 2010, p. 52).

No filme, o protagonista Gonzalo Infante (Matías Quer) e Pedro Machuca (Ariel Mateluna) são meninos de estratos sociais diferentes que, em 1973, vivem justamente essa transição entre o período democrático, sob a presidência de Salvador Allende, e o início da ditadura no Chile, com o general Augusto Pinochet. Eles se conhecem no Colégio Saint Patrick, um dos mais importantes da capital. O diretor do colégio, padre McEnroe, luta para integrar, na escola, diferentes camadas sociais, através da doação de bolsas de estudo a crianças carentes.

O filme teve uma grande preocupação em representar da forma mais crível possível aspectos da sociedade chilena da época. Um exemplo pode ser visto no figurino dos personagens. Maria Luiza, mãe de Gonzalo, veste-se com roupas de alfaiataria, costume comum das mulheres chilenas da classe média alta. $\mathrm{O}$ mesmo vale para os penteados, os carros e também os hábitos retratados.

Durante o governo de Salvador Allende ${ }^{2}$, Padre McEnroe, diretor do colégio Saint Patrick's, coloca em prática uma experiência nova: distribui algumas bolsas a alguns alunos carentes, moradores de comunidades ilegais em torno de Santiago. Essa prática existiu, 
de fato, e se inseria na nova política de cunho reformista do presidente do Chile: "[...] a ambição de Allende era ser o primeiro governante da história a conduzir seu povo ao socialismo por meio de uma via democrática" (WINN, 2010, p. 20), logo precisava solapar as distinções sociais e a educação seria via privilegiada para isso.

É esse o contexto retratado no filme, mote para a personagem Pedro Machuca parar na mesma sala de aula de Gonzalo. Logo em seguida, em um aparente paradoxo, eles se tornam amigos em uma briga. Pedro Machuca, garoto morador de uma comunidade ilegal, vem de família de baixa renda, com pai alcoólatra; sua mãe cuida das tarefas do lar e de seu irmão mais novo. Gonzalo vem de uma família de classe média alta, mas igualmente desestruturada. Dessa "luta de classes", nasce a amizade, mostrando a visão humanista de que, por baixo das diferenças aparentes, existe uma unidade essencial aos seres humanos. Uma relação fraternal emerge da busca pelo solapamento das diferenças na aparência e pela emergência de um universo de descobertas, como o da liberdade e o da sexualidade. Logo, meninos que começam brigando, aproximam-se. Dessa maneira, na mesma perspectiva de Ismail Xavier (2008, p. 35), o filme procura demonstrar que a questão da ditadura não se subscreveu apenas ao embate entre militares e subversivos, e atingiu todas as camadas da sociedade. Portanto, mais uma vez, a relação de dois garotos passa a ser um microcosmo de uma realidade muito maior, que poderia ser vista em qualquer lugar do Chile.

O diretor dá grande destaque, por exemplo, ao cenário e os personagens das poblaciónes. O termo población ${ }^{3}$ é um nome genérico para alguns bairros populares formados no inicio do século $\mathrm{XX}$, no Chile. Na maioria dos casos correspondeu a invasões, mais especificamente tomas de sitio que realizavam os sem teto. Complementando, Mário Garcés (2005) também denomina población como:

las urbanizaciones y la construcción de viviendas realizadas por el estado a partir de Planes Nacionales de Vivienda. La población tiene un gran contenido simbólico, ya que es la forma peculiar de habitar por parte de las mayorías pobres. En muchos casos, la "toma de sitios" es recordada por sus habitantes como el producto de su propia acción y protagonismo. 
Pelos olhos de uma criança: as ditaduras militares latino-americanas...

Ao contrário do núcleo familiar de Kamchatka, a família de Gonzalo passa por problemas conjugais: sua mãe, Maria Luiza Infante, possui um amante com o qual se encontra quase todas as tardes. Durante seus encontros, a mãe leva Gonzalo à casa de seu amante. Este oferece ao menino presentes muito caros em troca de seu silêncio sobre a relação extraconjugal da mãe. Vemos em Gonzalo uma solidão constante pela falta de amigos e pela desestruturação da família.

Seguindo o enredo do filme, Machuca vê em Gonzalo um companheiro pouco preocupado com a diferença social que os separa. Do mesmo modo, Gonzalo, menino solitário e que testemunha as infidelidades conjugais da própria mãe, encontra no companheirismo e compreensão de Machuca o apoio para sua solidão. Gonzalo carrega Machuca para todo lugar e lhe apresenta tudo aquilo a que tem acesso com dinheiro e fartura. Por sua vez, Machuca mostra ao colega todo o companheirismo e a dedicação que, diferentemente dos bens materiais, o dinheiro não pode comprar.

Na población, Gonzalo encontra um mundo totalmente diferente do seu. A casa de Machuca não possui os serviços básicos necessários como na casa de Infante. Não há um banheiro adequado, a comida não é farta, os cômodos são todos conjugados e ele brinca na rua. Apesar desse ambiente menos abastecido de bens materiais, Gonzalo se vê atraído pelo mundo de Machuca, pois nesse, ele possui amigos. Lá, conhece Silvana, prima de Machuca, uma garota extrovertida que mostra para Gonzalo os primeiros passos de uma relação sexual.

O mesmo acontece com Pedro Machuca: o mundo do amigo o atrai. Gonzalo tem conforto material, uma casa bem estruturada, muitos brinquedos, roupas caras, um quarto só para ele. Logo, um universo que aparenta ser mais bem estruturado que o seu. Entretanto, apesar dessa aparente dualidade entre os dois mundos apresentada pelo diretor, ao longo do filme descobrimos que ambos possuem famílias desestruturadas e são mais parecidos do que supõem de inicio. E é essa semelhança que sutilmente os une.

Mas essa ligação é desconstruída nas cenas finais do filme. A cidade de Santiago está em caos, com várias manifestações nas ruas. Essa é a perspectiva que nos mostra o diretor quando Pedro e Silvana levam Gonzalo para participar de passeatas. A crise chilena parece querer tomar o centro da narrativa, mas, na realidade, a pas- 
seata era o lugar onde os meninos pobres tiravam parte do sustento da família, vendendo bandeirinhas e cigarros aos manifestantes. Infante fica apreensivo neste universo de manifestações e pouco entende o que está em jogo: a questão social e política do Chile era um problema menor diante de suas descobertas, inseguranças e visão de mundo. Em um jogo de espelhos, a passeata torna-se meio para o desenvolvimento da trama de amizade dos personagens; a trama pessoal torna-se permeada por adversidades contextuais, como a pobreza, as manifestações políticas etc.

Em outras palavras, podemos ver como o contexto maior adentra o mundo privado das personagens principais. Ou seja, se o golpe (e a tensão antes dele) desviou o Chile de sua rota, também desviou o caminho dos indivíduos; a nação, portanto, não é um ser abstrato, entidade atemporal e metafísica que existe antes e para além de seus habitantes. Pelo contrário, a nação é a soma das vidas de seus habitantes. Logo, o que se passa na esfera individual é reflexo do que se passa na vida coletiva. E é nesse cenário que começaram os primeiros choques de diferenças sociais entre Gonzalo, Machuca e Silvana. À medida que o filme avança, o país divide-se cada vez mais entre os partidários e adeptos de Salvador Allende: o pai de Gonzalo é simpatizante de Allende, enquanto a mãe protesta contra a carestia e relaciona-se com um homem bem mais velho, rico e reacionário. O universo da escola e da adolescência, já marcado pelo conflito, passa a ter confrontos maiores entre os rapazes pobres e os ricos. Ainda assim, com esse acirramento de tensões pessoais e sociais, Gonzalo permanece simpático aos colegas de classe mais baixa e a Machuca, seu grande amigo.

Por fim, temos como desfecho o golpe militar. Depois do golpe, a mãe de Gonzalo definitivamente se junta ao seu amante, enquanto seu pai não retorna mais de sua viagem a Roma. No filme não fica claro o destino do pai. O diretor Andrés Wood opta deixar em suspense seu fim, mas se sugere que seu destino acaba se tornando um exílio, ou seja, se expressa o fim pelo tácito, pelo silêncio que acaba pressupondo o degredo. O que Gonzalo vê o transforma para o resto da vida e o obriga a viver com os traumas do passado, ou seja, com o peso de sua própria sobrevivência, separado de seu bom amigo Machuca.

Anos 90, Porto Alegre, v. 20, n. 38, p. 411-439, dez. 2013 
Pelos olhos de uma criança: as ditaduras militares latino-americanas...

\section{O ano em que meus pais saíram de férias: ditadura e copa do mundo aos olhos de uma criança}

Por sua vez, o longa-metragem brasileiro, $O$ ano em que meus pais saíram de férias, se passa em 1970, ano da Copa do Mundo do México. No filme, sempre que os jogos da seleção são transmitidos pela TV e rádio, as ruas ficam completamente vazias e todos os brasileiros se reúnem para torcer pela conquista da taça mundial. Entretanto, apesar da aparente união do país, aquele era o governo Médici, momento de milagre econômico e de aumento da censura, bem como de suspensão dos direitos políticos e civis dos cidadãos. O período após o quinto Ato Institucional marca uma fase do golpe no sentido de instrumentalização e efetivação dos aparatos repressivos e consequente erradicação dos grupos de luta armada urbana no país (SILVA, 2012, p. 511).

Os aparelhos repressores, que não estão explícitos todo o tempo, podem ser percebidos por meio do clima de tensão presente em diversos momentos. Apesar do estado de exceção visar muito mais "[...] os componentes insatisfeitos daquela grande e heterogênea frente que apoiara o golpe de 1964" (REIS, 2004, p. 52) e em contraponto haver perspectivas otimistas sobre o país, sobretudo a respeito do crescimento econômico, [...] comparado a um imenso canteiro de obras, foi tomado por incontida euforia desenvolvimentista" (REIS, 2004, p. 54-56). De acordo com Thadeu Almeida, eram tempos de comemorações, e elas se multiplicavam: em 1970 era o tricampeonato mundial de futebol; em 1971 rememoravam-se os 75 anos do cinema nacional; em 1972 foi a vez do Sesquicentenário da Independência do país, uma das maiores (ALMEIDA apud CORDEIRO, 2005, p. 106), se não a única, grande festa popular da ditadura.

O futebol é o fio condutor de toda história de Mauro (Michel Joelsas), um menino de 12 anos que foi deixado por seus pais em São Paulo na casa de seu avô. Os pais de Mauro, assim como em Kamchatka, também militam de alguma forma contra a ditadura e dizem para o menino que sairão de férias, deixando-o com o avô. $\mathrm{Na}$ verdade, essa é a saída que encontram para não dizer que estão fugindo da repressão dos militares e que precisam se esconder. $\mathrm{O}$ pai de Mauro promete ao menino voltar assim que começar a Copa 
do Mundo. O problema é que o avô do garoto acabara de morrer de ataque cardíaco naquele mesmo dia, sem que os pais soubessem. Mauro, então, fica aos cuidados de Scholomo, um solitário senhor judeu, vizinho de seu avô, interpretado por Paulo Autran.

Eles moram no bairro Bom Retiro, de grande tradição paulista no setor têxtil e que concentra grande comunidade judaica. Scholomo possui costumes culturais bastante diferentes dos de Mauro e isso torna a relação dos dois um pouco conflituosa, no inicio. Scholomo não quer cuidar de um gói e Mauro só quer saber da volta de seus pais, por isso não sai de perto do telefone.

O esporte não é apenas condutor da narrativa, mas também é uma metáfora da vida do menino. Mauro é apaixonado por futebol: vivia jogando futebol de botão com seu pai e ambos teciam comentários sobre a atual seleção. O desejo maior de Mauro é se tornar goleiro, depois de assistir uma partida entre os italianos e judeus no bairro. O garoto fica encantado com a "arma secreta" do time judeu, o talento do goleiro, único capaz de barrar os bons atacantes dos italianos. O goleiro é namorado de Irene, uma jovem que encanta todos os meninos do bairro, inclusive Mauro. Além de ter o coração de Irene, o goleiro destaca-se no jogo pelas suas defesas e por ser um negro em meio aos imigrantes italianos e judeus.

Mauro, abandonado pelos pais, um não-judeu, distante dos seus e de sua cultura, identifica-se com esse perfil e deseja ser o "negro voador", a profissão mais solitária dentro de um campo e que precisa resistir sempre. O envolvimento do garoto com os jogos transmitidos representa seu gosto pelo esporte, mas também marca a espera e o desenrolar dos fatos da ditadura ao longo do filme.

Os jogos de futebol também dividem os militantes e estudantes contrários à ditadura no filme. Estes não sabem se devem torcer pelo Brasil, pois consideravam a Copa do Mundo um instrumento de propaganda do regime militar, que dissimulava as mortes e o aumento da tortura aos presos políticos. Uma vitória da Tchecoslováquia no jogo contra a seleção do Brasil, por exemplo, representaria uma vitória contra a ditadura, por exemplo. Mas mesmo assim, no filme, a política é deixada de lado e todos comemoram o sucesso da virada da seleção naquele jogo. A guerra silenciosa que cercava o país passava despercebida nesse momento. 
Pelos olhos de uma criança: as ditaduras militares latino-americanas...

Apesar da solidão de Mauro, aos poucos o menino sai do apartamento e assiste, com os novos amigos, os jogos seguintes do selecionado brasileiro. Mauro conquista mais duas outras amizades importantes, além de Irene e Scholomo: Hanna, garota da sua idade e moradora do prédio. Ela é uma menina que lucra com os meninos do bairro, deixando-os espiar as mulheres trocando de roupa na loja de sua mãe. Assim como em Machuca, as primeiras experiências sexuais também fazem parte do enredo do filme.

Mauro também se torna amigo de Ítalo que, na verdade, é colega de militância de seu pai. O garoto não entende muito a relação dos dois adultos, mas se sente confortável com ela: estar próximo de Ítalo era uma forma de estar próximo do pai. Ítalo promete proteção a Mauro e este o ajuda quando é repreendido pela polícia após a invasão de uma faculdade. Ítalo, que está bastante ferido, se esconde na casa do avô de Mauro, com a conivência do garoto.

Essa relação entre Ítalo e Mauro revela outro tipo de conflito, apesar da segurança que o garoto sentia em estar próximo do amigo do pai: o laço de amizade estabelecido não podia ser completo. Mauro não conhecia nada sobre a vida do amigo protetor, sobre sua história de vida e até onde estava envolvido na militância política. Todo o cenário é retratado através de nuances, como em Kamchatkea, no qual vemos a relação estabelecida entre Harry e Lucas como uma amizade difícil de manter e permeada por mistérios.

No filme brasileiro, a consequência da relação entre Scholomo e Ítalo acaba levando o judeu à prisão, porque ele estava em constantes conversas com o militante à procura de notícia dos pais de Mauro. O momento da prisão e a volta de Scholomo são retratados através do silêncio. Nas cenas finais de Kamchatkea, como vimos, o silêncio também é o recurso narrativo empregado na cena em que os irmãos vão morar na casa dos avós e não sabemos quanto tempo duraria aquela separação entre as crianças e seus pais (embora paire a certeza de que pode ser perene e definitiva).

Nesse ponto, os três filmes aqui analisado têm pontos de muita proximidade. Harry, em Kamchatka, não vê mais seus pais, não sabe exatamente para onde eles foram e o silêncio da incerteza sugere que eles foram mortos pela ditadura e engrossaram a memória que dói na Argentina: a questão dos "desaparecidos". O 
pai de Mauro, em $O$ ano em que meus pais saíram de férias, também referência para o garoto, desaparece e acaba morto e Scholomo preso e torturado. A tortura fica implícita no desalinho e nos ferimentos vistos no personagem quando este, em silêncio, volta à casa depois de ser liberado. Isso revela-nos nosso passado que dói: os crimes de tortura e morte da ditadura, sempre silenciados pela lei de anistia. Já em Machuca também podemos fazer essa conexão, afinal Gonzalo aponta indiretamente o destino do pai como sendo o exílio na Itália.

O filme também tem um esforço de reconstituição cênica e ambientação. Um exemplo, para além de figurinos e cenários, é a música Pra frente Brasil, constantemente tocada nas rádios do filme como forma de representar a grande euforia com a Copa e o esforço do regime em exaltar a si próprio em época de milagre econômico. Os códigos visuais também são bastante explorados na película. Cao Hamburguer utiliza, principalmente, o efeito de sombra e iluminação. Quando Mauro chega ao prédio onde mora seu avô, por exemplo, o diretor trabalha com a penumbra, assim como na cena de Kamchatka em que Harry descobre que pertence a um mundo diferente de seu amigo, quando é proibido pela mãe de Bertuccio de visitá-lo.

Além disso, os cenários que ainda não foram apresentados ao público aparecem, pela primeira vez, por meio de reflexos em espelhos, como na cena inicial, na qual vemos Minas Gerais, lar do garoto, através do retrovisor do carro que o leva para longe dali. Seu passado ficando para trás, desconhecido para o expectador. Na chegada a São Paulo, a cidade, novo presente do garoto, nos é mostrada por meio do reflexo do vidro dianteiro do carro, por meio de seus arranha-céus.

Os recursos ao silêncio, ao não dito, como visto, são igualmente presentes. No final do filme, por exemplo, quando Mauro está assistindo a final do campeonato, vemos Scholomo saindo de um carro e voltando para sua casa após sua prisão. Ouvimos as pessoas comemorarem longinquamente o tricampeonato e tudo vai ficando em silêncio à medida que Mauro vai se aproximando da casa do judeu. Assim que o encontra, Scholomo o abraça e nada é falado na cena. O judeu encaminha o menino até o quarto. Mauro, tentando quebrar o clima de tensão, começa a narrar os momentos do 
jogo, ao passo que Scholomo permanece calado. Ao chegarem ao quarto, lá encontram a mãe de Mauro acompanhada de um médico. Pouco é falado na cena também. Mauro faz perguntas e não obtém as respostas, não sabe o porquê dos pais terem demorado tanto e por que seu pai não voltou com sua mãe. A única resposta que obtém é a de que seu pai está sempre atrasado. O reencontro é mostrado intercalado a imagens da conquista da taça do mundo. Neste momento, o futebol é deixado de lado por Mauro que, mesmo sem entender, acaba virando uma "coisa chamada exilado". A ditadura e seus efeitos, através dos olhos da criança, eram dilemas dos adultos.

\section{Os usos do passado: a ditadura entre o exílio e o desaparecimento.}

Como vimos, os três filmes conduzem suas narrativas centrados nos aspectos das mudanças psicológicas dos personagens e nas alterações de seus mundos privados como microcosmos de alterações maiores na sociedade. Como afirma Maria Luiza Rodrigues de Souza: "[...] as ficções cinematográficas, produzidas no período pós-ditatorial, são uma das formas de produção de novos sentidos em face à experiência da ditadura" (2007, p. 19). Cada filme oferece termos nos quais as relações sociais são reconstruídas e relidas através da interpretação que o cinema faz daquele passado.

Todos os elementos de mudança no cotidiano dos garotos dos filmes são fortes e indicam traumas que marcaram todos os personagens. Em comum, Harry, Mauro e Gonzalo são, ao mesmo tempo, protagonistas e narradores de suas vidas. De um lado, não entendem, pela inocência do olhar infantil, o que está acontecendo politicamente em seus países, ainda que Mauro tenha alguma consciência de um contexto maior do que o de alterações no seu cotidiano imediato. Por outro lado, todos sentem as alterações que geram incertezas diante das novas situações que lhes são outorgadas. Essas tensões pessoais são resolvidas ou encaradas através do olhar inocente de uma criança, que se contrasta com o do expectador, que já sabe o fim da história (ao menos em termos de macronarrativa).

Curioso é pensarmos que a incerteza quanto ao futuro vi- 
venciadas por Gonzalo, Mauro e Harry era a incerteza de muitos: ninguém sabia qual seria o futuro do Chile, do Brasil e da Argentina e que consequências haveria para o cenário sociopolítico de cada país. Além disso, as angústias infantis dos meninos fundem-se às incertezas do contexto: suas vidas tiveram seus horizontes expandidos por um lado (conheceram novas pessoas e mudaram os círculos de sociabilidade) e limitados ou desestabilizados por outro (o mundo conhecido esfacela-se e as relações pessoais diluídas passam a ser metáfora de um mundo que se dissolve frente à nova realidade trazida pelos golpes militares); nesse sentido, suas vidas são, de novo, um microcosmo do mundo que os cerca.

Nesse sentido, como já afirmamos, podemos pensar os filmes como obras de arte, e que, nesse sentido, fazem mais do que retratar o real. $\mathrm{Na}$ verdade, eles o reinventam ao usar os signos de forma ampla e aberta. Quando afirmamos que os filmes usam metáforas e que alguns personagens e situações são retratados de forma alegórica, temos que lembrar que essas são figuras de linguagem que combinam diferentes signos em expressões que solicitam um universo semântico amplo para que se estabeleça seu significado, proporcionando ao leitor/espectador um leque muito mais amplo de possibilidades de entendimento e de leitura do que simplesmente pensar o filme como retratado, fuga ou reflexo da realidade. "A ditadura", por exemplo, como alegoria, é um signo abstrato que, nos filmes, é "encarnada" em personagens e em situações, muitas vezes subentendidas ou apenas sugeridas.

Os filmes que têm aspectos autobiográficos são, portanto, a reelaboração de um discurso sobre o passado e uma releitura que busca dar sentido a um trauma social e político através da experiência pessoal de crianças (idade dos diretores e roteiristas à época). Os diretores dos três filmes elencados tratam um pouco da vivência de cada um. E desse modo, podemos pensar na dimensão autobiográfica de cada filme ancorado no debate entre o dever de se dizer a verdade e seu limite. Nesse sentido, os filmes constroem formas de pensar o passado que ressaltam aspectos e silenciam outros, baseados, em parte, nas vivências em que os diretores afirmam guiar algumas de suas escolhas narrativas. Com isso, não afirmamos que filmes apagam certos aspectos ou que 
Pelos olhos de uma criança: as ditaduras militares latino-americanas...

silenciam outros. Mais detidamente, como alerta Tzevan Todorov, "[...] a memória não se opõe absolutamente ao esquecimento. Os dois termos contrastantes são o apagamento (o esquecimento) e a conservação; a memória é, sempre e necessariamente, uma interação entre os dois" (TODOROV, 1995, p. 14).

Como propõe Maria Paulo Araújo, hoje, os processos de redemocratização e de pactuação política estão sendo vividos de maneira fortemente influenciada pela questão da violência: as desigualdades sociais, a corrupção, a criminalidade e a explosão caótica urbana. Além disso, a violência do passado assombra o presente: os mortos, os desaparecidos e os torturados (ARAÚJO, 2008, p. 273). Nesse sentido, os filmes analisados convidam a uma reflexão e rememoração sobre os crimes de tortura durante aquela época. A palavra que melhor descreve essa herança indesejada é "violência", que deixou viva as marcas do passado no presente, e naqueles personagens.

No artigo O Preço de uma Reconciliação Extorquida, Jeanne Marie Gagnebin (2008) elabora uma análise a respeito das formas de se esquecer. Para ela, a imposição do esquecimento como uma forma de ignorar um fato acaba por impor uma única forma de lembrar e assim esta memória vai lutar para retornar. Mas isso não significa que os fatos não devam ser esclarecidos. Pelo contrário, provoca uma lembrança constante e incita a repetição de novas formas de exclusão e de atrocidades em quaisquer regimes políticos. Maria Rita Kehl em Tortura e Sintoma Social (2008) compartilha da mesma ideia: deixar os sintomas sociais não tratados pode promover uma ampliação da "barbárie". Além disso, engendraria um inconsciente coletivamente sustentado.

Assim, aqueles que foram vitimizados com a violência ou aqueles que se transformaram em assassinos e torturadores ficam com uma "sensação de irrealidade", segundo Kehl, uma vez que são marcados pela indiferença por aqueles que não se predispõem a testemunhar o trauma. Verifica-se, portanto, que há uma crise ética contemporânea e uma banalização da violência, ou seja, a naturalização da tortura pode ser um sintoma de projeção da frustração ou o resultado de um apelo social.

Como propões Marcos Napolitano: “[...] o filme como um documento não pode ser analisado de forma isolada; ele deve ser 
confrontado com seu processo criativo, com o campo cultural e com as condições sociais de sua produção" (2007, p. 65) É preciso localizar o papel e o lugar de fala de seus produtores. Michel de Certeau (1982, p. 65), analisando as operações historiográficas, considera que "[...] certamente não existem considerações, por mais gerais que sejam, nem leituras, tanto quanto se possa estendê-las, capazes de suprimir a particularidade do lugar de onde falo e do domínio em que realizo uma investigação". Podemos pensar que o mesmo se aplica a narrativa desse tipo de filme, na qual questões pessoais ou de vivência do diretor, como no caso de Machuca, por exemplo, atuam como formas de reorganizar o passado, ainda que em um relato ficcional. Andrés Wood, assim como o personagem principal, Gonzalo, estudou em um colégio de classe média alta e foi colega de sala de alguns alunos com baixos recursos agraciados com bolsas de estudos no período do governo de Salvador Allende. A história do filme foi criada a partir de uma experiência vivida pelo próprio diretor, segundo ele mesmo deixou claro em entrevistas.

Os eventos descritos em Kamchatke também são uma tentativa do diretor (e roteirista) de entrelaçar realidade e ficção. A situação da família de Harry é semelhante à da família de Pyñero, que conviveu com uma família clandestina como a do filme:

Quando eu tinha 19 ou 20 anos, eu conheci pessoas assim. Era uma família, que eu nunca soube o nome, nem sabia o que aconteceu com eles, com quem eu passei dois dias - menos tempo do que o personagem de Lucas no filme. Lembro-me da grande harmonia e amor feroz dos pais para com seus filhos. Eu nunca vivi na clandestinidade, mas eu tinha minha família e amigos que se encontravam nesta situação. Para mim, eles me deram uma nomeação em um canto da rua, entrei no carro, eu tinha que curvar a cabeça, os militares fizeram um desvio, pois estavam fazendo uma operação. É por isso que Kamchatka não é uma ficção baseada em uma história real, mas sim um resultado de ficção cheio de histórias verdadeiras. ${ }^{4}$ 
Pelos olhos de uma criança: as ditaduras militares latino-americanas...

Mas apesar do filme ter como tema a ditadura, Marcelo Pineyro explica que Kamchatka não pode ser limitado a essa dimensão. Para ele, como procuramos deixar claro aqui, as relações entre pai e filho falam mais alto que os efeitos do regime.

O mineiro Cao Hamburguer viu o pai Ernest Hamburguer, judeu, e a mãe Amélia Hamburguer, católica, serem presos na ditadura e, assim como Mauro, também atuou como goleiro no time da infância. "Essa passagem é tabu na família", explica ele. "Raramente conversamos a respeito disso, e minhas lembranças são meio nebulosas." Na memória do diretor, ele tinha por volta de 8 anos quando seus pais, um casal de físicos e professores da USP, desapareceram por algumas semanas. Nesse período, Hamburguer e os quatro irmãos ficaram sob os cuidados das avós, a judia Charlotte e a católica Helena. "Quando voltou, minha mãe não saía da cama”, contou com a voz embargada à revista Veja: "Dormia o tempo todo, dia e noite"

Logo, as demais coincidências narrativas entre os três filmes se fazem entender: todos os protagonistas vivem com outras pessoas e crianças, mas, em algum momento, sentem-se em um mundo solitário, de imaginação. Vivem, como toda criança, cheios de desejos e de descobertas, mas também experimentam angústias e novas tensões que foram específicas de um contexto maior do que o da escola e dos demais círculos de sociabilidade imediatos.

O olhar infantil pode, pois, num primeiro momento, parecer apenas uma releitura da experiência ditatorial pelo viés da inocência, sendo nesse sentido opaca e tola. Mas, como estamos sugerindo, ao falar da ditadura através de crianças, os filmes estão tratando alegoricamente de realidades mais amplas, usando a quebra da inocência como metáfora. E, nesse sentido, são documentos para o historiador buscar compreender como têm sido elaboradas algumas das representações dos governos militares em um período democrático.

Portanto, o que estamos sugerindo é que, para além da fruição estética ou de interpretações simplistas e factuais ("o que está certo e o que está errado nos filmes em relação ao período e como ele de fato foi'), a compreensão dos filmes deve passar por qual o papel dos filmes como releitura do passado na sociedade atual, em busca ela própria de repensar seus traumas em relação à ditadura. Em nosso presente, permanece uma ferida aberta, um passado que 
dói, e é neste contexto, pela busca do reforço da identidade e pelo trabalho de memória, que uma enorme quantidade de filmes sobre a ditadura estão sendo feitas, geralmente por diretores que viveram o processo quando ainda eram crianças.

Embora possamos perceber diferenças na forma pela qual Argentina, Chile e Brasil lidaram e lidam com seu passado recente, há muitas similitudes nos processos. No Brasil e no Chile, a ditadura aparece por meio do exílio, mais do que pelos desaparecidos. $\mathrm{Na}$ Argentina, o contrário. Ainda assim, em todos os filmes, há "o dever de memória", a obrigação permanente de se lembrar dos feitos realizados como condição de encontrar um lugar para o passado no presente. "É esse trabalho de evocação o único caminho que presentifica de certa maneira o passado, tornando-o efetivamente um objeto de inquirição" (GUIMARÃES, 2007, p. 26)

$\mathrm{Na}$ esteira do "dever de memória", especialmente em um mundo pós-Holocausto e nos seus desdobramentos de experiências traumáticas, Manoel Salgado Guimarães nos lembra que

temos um retorno do "eu" e das subjetividades como critério de legitimação dos discursos sobre o passado, assim como a sobrevalorização do testemunho como fonte capaz de assegurar a veracidade das falas sobre o passado. Esse eu que ficara alijado da história retorna à cena quando as críticas às diferentes formas de estruturalismo se fazem presentes no cenário das ciências humanas a partir dos anos 1970. Uma filosofia do sujeito acompanhava o primado do político como forma de inteligibilidade da organização social. Esse movimento se fez acompanhar pela crescente importância do conceito de representação para pensar a vida social (GUIMARÃES, 2007, p. 28).

Mas o que é pensar esses discursos sobre os governos da ditadura do século XX, construídos em nosso tempo? Não existe, certamente, uma hierarquização em termos de qualidade ou veracidade do que é produzido acerca dessa memória nas várias formas de leitura e de usos do passado. Seja no cinema, seja na academia, o passado é reconstruído com finalidade, intencionalidade e sob 
determinados projetos políticos. Como Beatriz Sarlo nos lembra, o testemunho é outro fator em comum entre as diversas formas de narrativa sobre esse passado recente, dado que outro tipo de documentação é enviesada, censurada ou não aberta à pesquisa. Portanto, nesse caso, o testemunho apresenta-se "[...] como instrumentos de verdade [...]", para libertar "[...] os direitos reprimidos que devem se liberta [...]" (SARLO, 2007, p. 39).

Pensando nesta noção de testemunho proposta por Sarlo, podemos relacionar sobre o ato de testemunhar discutido em Hannah Arendt (1974, p. 285), no que ele se refere à relação entre memória e história:

nenhum mundo humano destinado a perdurar após o curto período de vida dos mortais seria capaz de sobreviver sem que os homens estivessem propensos a fazer aquilo que Heródoto foi o primeiro a empreender conscientemente, a saber, [...] dizer o que é. Nenhuma permanência, nenhuma perseverança da existência podem ser concebidas sem homens decididos a testemunhar.

Para a filósofa, é fundamental que haja a articulação do passado com a ação política no presente. A autora identifica na trajetória política do mundo contemporâneo, sob a ótica do totalitarismo do século XX, uma ruptura entre passado e futuro. Para ela, o ser humano é incapaz de se reconhecer no mundo, mas o pensamento, enraizado na particularidade e na contingência da experiência, é um modo fundamental da abertura do espírito em relação ao mundo. Essa ruptura não permite que acessemos o passado e suas tradições sem o conhecimento do nosso legado que, segundo a autora, está dissolvido em "memórias oficiais", impelindo-nos para uma ação consciente no futuro.

Eleger para discussão "o passado que ainda dói no presente" é inteiramente cabível tanto à linguagem fílmica quanto à acadêmica, malgrado as diferenças epistêmicas entre elas. Nesse sentido, ambas lançam discussão sobre o que foi e o que significou o regime militar para o presente, problematizando a memória sobre aquele contexto e ensejando reflexão. 
Assim como já mencionado no trabalho, compreendemos que pensar "[...] o filme como documento pode encenar o passado e possuir seu estatuto como objeto da cultura" (CAPELATO, 2007, p. 10). Mas, além disso, os filmes também oferecem uma reflexão sobre uma época, através da veiculação de valores, projetos e intencionalidades, servindo, pois, ao historiador como fonte histórica não sobre o tema que retrata, mas sobre o período em que foi feito.

Nos dois países, a lenta consolidação da democracia, nas décadas de 1980 e 1990, permitiu a instauração de debates a respeito dos problemas herdados pela ordem anterior em várias esferas da sociedade, entre elas as artes. O cinema sobre a ditadura tornou-se campo privilegiado, levantando questões tanto em documentários quanto em filmes ficcionais. Devido a sua grande recorrência, proporcionou uma diversidade de olhares e diferentes formas de representação, dentre essas as que ocorrem no momento atual, onde as injustiças e crimes daquela época continuam em evidência, porém, com uma vertente atualizada a que se convencionou chamar de retomada e de nova onda argentina. A frequência desse assunto no cinema revela a dificuldade de solucionar o traumático quadro deixado pela violência do passado autoritário e que revela a necessidade de debatê-lo abertamente, contribuindo, à sua maneira, para discutir o panorama de injustiça perante questões que permanecem vivas e sem solução. Trata-se, portanto, de um diálogo político que responde a uma questão há muito tempo recorrente, cujos propósitos e estruturas variam e geram diferentes pontos de vista nas obras com estruturas narrativas, opções estéticas e implicações ideológicas bastante distintas.

A escrita filmica da ditadura, tomando como base os filmes trabalhados, permite compreender como os filmes atuam como fontes de representações da ditadura militar latino-americana e carregam consigo um debate acerca da memória e da história. No contexto pós-ditatorial, os filmes se articulam enquanto "[...] discursos da memória [...]" (SARLO, 2007, p. 57-59). Logo, um filme como documento não pode ser analisado de forma isolada; ele deve ser confrontado com o processo criativo, com o campo cultural e com as condições sociais de sua produção. 


\section{THROUGH THE EYES OF A CHILD: THE LATIN AMERICAN MILITARY DICTATORSHIPS IN CONTEMPORARY CINEMA}

In this article, our goal is to discuss how some directors have portrayed the recent past of military dictatorships. We have approached the theme from a common perspective some films have: a discursive strategy to assemble movies from the angle of children protagonists. Therefore we will discuss the debate between history and cinema, and analyze the films: Kamchatka (Marcelo Piñeyro, Argentina, 2002), Machuca (Andrés Wood, Chile, 2004) and The Year My Parents Went on Vacation (Cao Hamburger, Brazil, 2006). We will verify how, when dealing with "painful pasts", with an object still hot, the children perspective ensnares the narrative in an aura of lost innocence and end of infant illusions through a traumatic experience. And the personal trauma becomes the metonymy (often autobiographical) of what is seen as a collective trauma.

Keywords: Dictatorship. Latin America. Memory. Movies. Childhood.

\section{Notas:}

${ }^{1}$ Termos utilizados por: CARDOSO, Irene. Para uma crítica do presente. São Paulo,: Ed. 34, 2001, 286 p.

${ }^{2}$ Salvador Allende era membro da Unidade Popular, e representava a primeira vitória significativa dos partidos políticos de esquerda em âmbito federal desde os anos 1940. Suas mudanças estruturais como a Reforma Agrária, a nacionalização de bancos, as minas e indústrias definiam o rumo da Revolução por meio de uma via democrática (WINN, 2010, p.20).

3 Tomamos como referencial o conceito de población proposto por Mario Garcés em Los caminos de la historia y la memoria em Chile, bairros das classes trabalhadoras constituídos entre 1930 e 1950 , ficam próximos as indústrias em torno da cidade de Santiago (GARCÉS, 2005). Para uma visão mais ampla das poblaciones e do movimento dos colonos, ver Mario Garcés em História do movimento de pessoas de Santiago, 1957-1970. Santiago: LOM, 2002.

${ }^{4} \mathrm{O}$ diretor de $\mathrm{O}$ ano que meus pais saíram de férias, Cao Hamburguer em entrevista concedida ao site: <http://lesenfantsducinema.free.fr/2009/films/film14/references.htm>. Acessado em: 21 mar. 2012.

${ }^{5} \mathrm{O}$ diretor de Kamchatcka, Marcelo Piñeyro em entrevista concedida ao site <http://vejasp.abril.com.br/revista/edicao-1983/cao-hamburguer-emociona-sao-paulo-com-novo-filme>. Acesso em: 21 fev. 2012. 


\section{Referências}

ALMEIDA, Adjovanes Thadeu. O regime militar em festa: as comemorações do Sesquicentenário da Independência brasileira. In: FREIXO, Adriano de; MUNTEAL FILHO, Oswaldo (org.). A ditadura em debate: Estado e sociedade nos anos de autoritarismo. Rio de Janeiro: Contraponto, 2005.

ARAÚJO, Maria Paula. Esquerdas, juventude e radicalidade na América Latina nos anos de 1960 e 1970. In: FICO, Carlos et al. Ditadura e Democracia na América Latina: Balanço histórico e perspectivas. 1. ed. [S.1.]: FGV, 2008. Cap. 10, p. 247-274 ARENDT, Hanna. Entre o passado e o presente. São Paulo: Ed. Perspectiva, 1974, p. 284.

BOPPRÉ, Fernando C. Tempo passado: cultura da memória e guinada subjetiva: um contraponto ao boom da memória nos estudos históricas. Revista Esboços. ISSN 20.

CALVEIRO, Pilar. Política y/o violência. Una aproximación a la guerrilla de los años 70. Buenos Aires: Grupo Editorial Norma, 2005.

CAPELATO, Maria Helena et al. História e cinema: São Paulo: Alameda, 2007.

CARDOSO, Irene. Para uma crítica do presente, São Paulo: Ed. 34, 2001, p. 286

CERTEAU, Michel de. A Escrita da História. Rio de Janeiro: Forense Universitária, 1982, p. 65-67.

CORDEIRO, Janaína Martins. Anos de Chumbo ou anos de ouro? A memória social sobre o governo Médici. Estud. Hist. (RIO. J) online 2009, v. 22, n. 43, p. 85-104.

FREDRIGO, Fabiana de Souza. 1998. Franca: UNESP, 1998.

FREDRIGO, Fabiana de Souza. "A influência das mobilizações sociais nas transições à democracia: o caso chileno".In: Caminhos da História da América no Brasil: tendências e encontros de um campo historiográfico. ALMEIDA, Jaime de (org.). Brasília: ANPHLAC, 2005. p. 20.

GAGNEBIN, Jeanne Marie. O preço de uma reconciliação extorquida. In: TELES, Edson; SAFATLE, Vladimir (org.). O que resta da ditadura. [S.1.]: Boitempo, 2008.

GARCÉS, Mario. Historia y memoria del 11 de septiembre de 1973 en la población La Legua de Santiago de Chile, 2005. Disponivel em: <http://www.historizarelpasadovivo.cl/downloads/garces.pdf>. Acesso em: 22 maio 2011.

GUIMARÃES, Manoel Luiz Salgado. O presente do passado: as artes de Clio em tempos de memória. In: ABREU, Martha; SOIHET, Rachel; GONTIJO, Rebeca (Org.). Cultura política e leituras do passado: historiografia e ensino de História. Rio de Janeiro: Civilização Brasileira, 2007. p. 23-42. 
JÚNIOR, Francisco das Chagas Fernandes. Cinema e Historiografia: trajetória de um obejto historiográfico (1971-2010). História da Historiografia, Ouro Preto, n,8., Abr. 2012, p. 151-173. Disponível em: < http://www.labhoi.uff.br/sites/default/ files/oficina_do_labhoi_no_2_-_historia_e_cinema.pdf $>$. Acesso em: maio 2012 KAMCHATKA. Direção: Marcelo Piñeyro. Produção: Pablo Bossi, Óscar Kramer, Francisco Ramos. Intérpretes: Ricardo Darín, Cecilia Roth, Héctor Alterio, Fernanda Mistral, Tomás Fonzi, Mónica Scapparone, Milton De La Canal, Matías Del Pozo. Roteiro: Marcelo Figueras, Marcelo Piñeyro. Alquimia Cinema S.A.; Oscar Kramer S.A., Patagonik Film Group; Telévision Española, 2002. Via digital (105 min.).

KEHL, Maria Rita. Tortura e sintoma social. In: TELES, Edson; SAFATLE, Vladimir (org.). O que resta da ditadura. [S.1.]: Boitempo, 2008.

KORNIS, Mônica Almeida. Cinema e História: um debate metodológico. Rio de Janeiro: Estudos Históricos, v. 5, 1992. 24 p.

MACHUCA. Direção: Andrés Wood. Produção: Gerardo Herrero, Mamoun Hassan, Andrés Wood. Intérpretes: Matías Quer, Ariel Mateluna Martelli, Aline Küppenheim, Ernesto Malbran, Francisco Reyes, Andrea García-Huidobro, Pablo Krögh Federico Luppi, Gabriela Medina. Roteiro: Roberto Brodsky, Mamoun Hassan, Andrés Wood. Santiago: Buena Vista International, 2004. 1 DVD (120 min.).

NAPOLITANO, Marcos. A escrita filmica da história e a monumentalização do passado: uma análise comparada de Amistad e Danton. In: CAPELATO, Maria Helena; MORRETIN, Eduardo; NAPOLITANO, Marcos; SALIBA, Elias Thomé (Org.). História e Cinema: dimensões históricas do audiovisual. São Paulo: Alameda, 2007. p. 65.

NÓVOA, Jorge Luiz Bezerra. Apologia da relação cinema-história. O olho da História, v. 1, n. 1, p.109-122, 1995. Disponível em; <http:// www/oolhodahistoria.ufba.br/01apolog.html>. Acesso em: maio 2012.

O ANO em que meus pais saíram de férias. Direção: Cao Hamburguer. Produção: Caio Gullane, Cao Hamburguer e Fabiano Gullane. Intérpretes: Michel Joelsas, Germano Haiut, Daniela Piepszyk, Caio Blat, Paulo Autran, Simone Spoladore, Eduardo Moreira, Liliana Castro. Roteiro: Cláudio Galperin, Bráulio Mantovani, Anna Muylaert e Cao Hamburguer. Rio de Janeiro: Buena Vista International, 2006. 1 DVD (110 min.).

REIS, Daniel Aarão. Ditadura e sociedade: as reconstruções da memória. In: REIS, Daniel Aarão; RIDENTI, Marcelo; MOTTA, Rodrigo Patto Sá. O golpe militar e a ditadura: quarenta anos depois (1964-2004). São Paulo: Edusc, 2004. RICOUER, Paul. A Memória, a história, o esquecimento. Campinas: Unicamp, 2007. 
ROLLEMBERG, Denise. "Esquecimento das memórias". In: MARTINS FILHO, João Roberto. O golpe de 1964 e o regime militar: novas perspectivas. São Carlos: Ed. UFSCar, 2006. p. 81-91. SARLO, Beatriz. Tempo passado: cultura da memória e guinada subjetiva. São Paulo.

ROMERO, Luis Alberto. A memória, o historiador e o cidadão. A memória do Proceso argentino e os problemas da democracia. Topoi, v. 8, n. 15, jul. 2007.

SARLO, Beatriz. Tempo passado: cultura da memória e guinada subjetiva. São Paulo: Companhia das Letras, 2007.

SOUZA, Maria Luiza Rodrigues. Um Estudo das Narrativas Cinematográficas sobre as Ditaduras Militares no Brasil ( 1964 - 1985) e na Argentina (1976 -1983). 234 fl. Tese (Doutorado em Ciências Sociais) Universidade de Brasilia, Brasilia, 2007. SILVA, Oliveira Walkiria. Construções de memórias da Ditadura Militar Brasileira: entre o trauma e o esquecimento. Cad. Pesq. Cdhis, Uberlândia, v.23, n.2, jul./dez. 2010.

SORLIN, Pierre. Sociologie du Cinéma. Paris, Aubier: 1982. Terceira parte, II Filme e Ideologia, estabelecimento de uma amostra, a construção tempo-espaço, pontos de fixação, sistemas relacionais, p. 199-205, 218-242.

TODOROV, T. Les abus de la mémoire. Paris: Éditions Arléa, 1995.

XAVIER, Ismail. O Discurso cinematográfico: A opacidade e a transparencia. 4. ed. [S.l.]: Paz e Terra, 2008.

WINN, Peter. A Revolução Chilena. 1. ed. [S.1.]: Unesp, 2010.

Recebido em: 30 de maio de 2012. Aprovado em: 02 de outubro de 2012. 